\title{
CARACTERÍSTICAS MORFOLÓGICAS E FISIOLÓGICAS DEISOLADOS DE Colletotrichum ASSOCIADOS À ANTRACNOSE DA ERVA-MATE
}

\author{
Morphological and physiological characteristics of Colletotrichum isolates associated to \\ yerba mate anthracnose
}

\author{
Valdomiro Bilenki Junior ${ }^{1}$, Celso Garcia Auer ${ }^{2}$, Neumar Irineu Wolf ${ }^{3}{ }^{3}$ \\ ${ }^{1,3}$ Centro Universitário Vale do Iguaçu, União da Vitória, Paraná, Brasil - \\ valdomirobilenki@uniguacu.edu\&neumarwolff@uol.com.br \\ ${ }^{2}$ Embrapa Florestas, Colombo, Paraná, Brasil - celso.auer@embrapa.br
}

RESUMO

\begin{abstract}
O valor histórico, cultural e econômico da erva mate a tornam uma espécie florestal de rara importância. A cultura é atacada por inúmeras doenças de natureza fúngica, destacando-se a antracnose, cujo agente causal pertence ao gênero Colletotrichum. Com o objetivo de fazer a caracterização morfológica e fisiológica de isolados de Colletotrichum, materiais com sintomas típicos da doença foram coletados em quatro diferentes municípios do Paraná: Colombo, União da Vitória, Cruz Machado e Guarapuava. As amostras foram processadas no Laboratório de Patologia Florestal da Embrapa Florestas, Colombo PR através dos métodos direto (tecidos doentes mantidos em câmara úmida constituída de caixas gerbox com papel mata-borrão umedecido com água ultrapurificada) e indireto (fragmentos de tecido doente superficialmente descontaminados, seguido de plaqueamento em meio de cultura Batata-Dextrose-Ágar mais antibiótico). A coloração das colônias variou de laranja a salmão e os tipos de conídios encontrados foram: cilíndrico, fusiforme, cilíndrico com ápice arredondado e ovoide. Houve diferença estatística entre os isolados quanto à temperatura de cultivo; a temperatura ótima para os isolados de União da Vitória, Colombo e Cruz Machado foi de $23^{\circ} \mathrm{C}$ e $22,6^{\circ} \mathrm{C}$ e para o isolado de Guarapuava $22,6^{\circ} \mathrm{C}$.
\end{abstract}

Palavras-chave: Crescimento micelial, Esporulação, Fitopatógeno, Temperatura ótima.

\section{ABSTRACT}

The historical, cultural and economic value of yerba mate makes it a forest species of rare importance. The crop is affected by numerous fungal diseases, especially anthracnose, whose causal agent belongs to the genus Colletotrichum. With the aim of carried out the morphological and physiological characterization of Colletotrichum isolates, materials with typical symptoms of the disease were collected in four municipalities of Paraná: Colombo, União da Vitória, Cruz Machado and Guarapuava. The samples were processed in the Forest Pathology Laboratory of Embrapa Florestas, Colombo- PR using the direct method (diseased tissues kept in a humid chamber constituted by gerbox boxes with blotting paper moistened with ultrapurified water) and indirect method (fragments of diseased tissue superficially decontaminated, followed by plating in culture medium Potato-Dextrose-Agar more antibiotic). Colony coloou varied of orange to salmon and the types of conidia found were cylindrical, spindle-shaped, cylindrical with rounded apex and ovoid. There is a statistical difference between the isolates in terms the cultivation temperature; the optimum temperature for the isolates from União da Vitória, Colombo e Cruz Machado was $23^{\circ} \mathrm{C}$ and for the isolated from Guarapuava $22.6^{\circ} \mathrm{C}$.

Keywords: Mycelial growth, Optimal temperature, Phytopathogen, Sporulation. 


\section{INTRODUÇÃO}

Muito embora a bebida produzida a partir das folhas deerva-mate (Ilex paraguariensis St. Hil.) seja consumida há séculos, foi somente a partir das duas últimas décadas que seus componentes passaram a ser investigados cientificamente (LUTOMSKI et al., 2020). Entre estes componentes, as xantinas (cafeína e teobromina), pilifenóis (flavonóides, taninos etc.) e as saponinas são as mais conhecidas. Alguns desses compostos possuem várias atividades biológicas, antioxidantes (COLPO, 2012) anti-inflamatórias e anticarcinogênicas (PUANGPRAPHANT, 2011) além de estimulantedo sistema nervoso central. Trata-se de uma planta cuja diversidade de compostos químicos traz inúmeras possibilidades de uso e a torna uma espécieflorestal rara pela importância de seu papel histórico, social e ambiental (PORFÍRIO-DASILVA et al., 2016).

Inúmeras pragas e doenças atacam a cultura tanto na fase de mudas (viveiro) como em árvores jovens (campo nativo e plantios comerciais) segundo Penteado Junior \& Goulart (2019). A antracnose é uma das principais doenças que afetam a cultura da erva mate (AUER \& SANTOS, 2016; WENDLING et al., 2020), cujo agente etiológico foi inicialmente identificado como Colletotrichum yerbaeSpeg. e no Brasil como Colletotrichum acutatum Simmonds (GOMES et al., 2001). O gênero Colletotrichum corresponde à fase anamórfica dos fungos do gênero Glomerella, cuja classificação taxonômica compreende o Reino Fungi, Filo Ascomycota, ordem Glomerelalles, e familia Glomerallaceae (AMORIM et al., 2018)

A antracnose é uma doença que ocorre principalmente nas folhas novas de mudas e em brotações pós-colheita em plantas adultas. Em plântulas e mudas, a doença se caracteriza pela presença de manchas necróticas escuras e irregulares podendo causar a morte do ápice das plantas; quando a lesão atinge tecidos ainda tenros das folhas, local onde geralmente ocorre a infecção, o ataque causa a deformação das mesmas (AUER \& SANTOS, 2016).

O primeiro relato dessa doença em erva-mate foi feito por Carlos Spegazzini (1908) em um trabalho intitulado "Hongos de la yerba mate" realizado na província de Missiones, Argentina (AUER \& SANTOS, 2016). O trabalho listou um total de 72 fungos associados à erva-mate. Ele atribuiu ao fungo causador da antracnose o nome de $C$. yerbae. De acordo com Cannon et al. (2012), nessa época havia uma forte crença de que espécies de Colletotrichum possuíam alta especificidade de hospedeiro, dessa forma um novo táxon era levantado sempre que o fungo era encontrado causando doença em um hospedeiro diferente.

Em função dos relatos produtores de erva-mate acerca da ocorrência de antracnose em mudas e plantas no verão de 2020/2021, fez-se um estudo sobre o agente causal de antracnose. O presente trabalho objetivou realizar a coleta, caracterização morfológica, cultural e fisiológica, de isolados de Colletotrichum spp. associados a antracnose em erva-mate no Estado do Paraná.

\section{MATERIAL E MÉTODOS}

Este trabalho foi conduzido no Laboratório do Centro Universitário Vale do Iguaçu - Uniguaçu, União da Vitória/PR e no Laboratório de Patologia Florestal da Embrapa Florestas, Colombo/PR. Os isolados foram obtidos de mudas (viveiro) e de árvores jovens (nativas e plantios comerciais) de erva mate (Tabela 01). Foram coletadas folhas, ápices de brotações e ramos herbáceos que apresentavam os sintomas típicos da doença (manchas necróticas escuras, deformação de folhas jovens e queima de ponteiros) em União da Vitória, Cruz Machado, Colombo e Guarapuava, Estado do Paraná.

Tabela 1. Identificação do isolado, múnicipio (PR), tipo de material coletado e estádio fenológico das plantas de erva-mate das quais os isolados de Colletotrichum spp. foram obtidos.

\begin{tabular}{ccc}
\hline Identificação & Múnicipio (PR) & $\begin{array}{c}\text { Tipo de material } \\
\text { coletado }\end{array}$ \\
\hline CM-a1/CM-a2/CM-a3 & Cruz Machado & $\begin{array}{c}\text { Folha e ápice de } \\
\text { brotações }\end{array}$ \\
CM-b1/CM-b2* & Cruz Machado & $\begin{array}{c}\text { Folha e ápice de } \\
\text { brotações }\end{array}$ \\
UV-1* & União da Vitória & $\begin{array}{c}\text { Folha e ápice de } \\
\text { brotações }\end{array}$ \\
UV-2 & União da Vitória & Folhas novas \\
GUA-1* & Guarapuava & Folhas novas \\
COL-1* & Colombo & Folhas novas \\
\hline
\end{tabular}

As amostras foram processadas através do isolamento direto (tecidos doentes mantidos em câmara úmida constituída de caixas gerbox com papel mataborrão umedecido com água ultrapurificada) e indireto (fragmentos de tecido doente superficialmente descontaminados por imersão em álcool $70 \%$ por $30 \mathrm{~s}$ mais $1 \mathrm{~min}$ em solução de hipoclorito de sódio a $1 \%$, seguida de plaqueamento em meio de cultura BatataDextrose-Ágar (BDA) mais antibiótico (ampicilina 80 ppm e cloranfenicol $40 \mathrm{ppm}$ ). As placas foram incubadas por quatro dias a $24{ }^{\circ} \mathrm{C}$, sob fotoperíodo de $12 \mathrm{~h}$, e depois os fungos foram repicados para purificação das colônias. 
Para identificação do patógeno à nível de gênero, foram confeccionadas lâminas para exame ao microscópio ótico, utilizando-se de glicerina como veículo de montagem.

A análise morfológica (tipo e forma do conídio) e da cultura (coloração, topografia e densidade da colônia) foi realizada para nove isolados de Colletotrichum. Para tal, os isolados foram repicados para placas de Petri com meio BDA e incubadas por sete dias a $24{ }^{\circ} \mathrm{C}$, fotoperíodo de 12 h. O tipo de conídio foi avaliado com auxílio de microscópio ótico e as características culturais avaliadas por meio de análise visual. A coloração das culturas foi baseada na avaliação visual (Munsell color chart) descrita por Silva (2016) para isolados de Colletotrichum spp., obtidos de Capsicum chinense Jacq.

Para a caracteristica altura de crescimento das colônias, adotou se como critério a divisão da altura livre da placa de Petri em quatro partes, sendo considerado rente quando não era possivel avaliar a altura de crescimento, baixo para menos de $1 / 4$ e médio para altura de crescimentio entre $1 / 4$ e $1 / 2$ da altura da placa.

$O$ ensaio de temperatura foi realizado para um isolado de cada procedência (Cruz Machado, União da Vitória, Colombo e Guarapuava). Esses isolados foram repicados para novas placas com meio BDA com o objetivo de gerar a fonte de inóculo para os ensaios. Após sete dias de incubação a $24^{\circ} \mathrm{C}$, fotoperíodo de $12 \mathrm{~h}$, discos de micélio foram depositados no centro das placas de Petri contendo meio BDA e incubados em cinco temperaturas diferentes $\left(16,20,24,28\right.$ e $\left.32^{\circ} \mathrm{C}\right)$. O delineamento utilizado foi o inteiramente casualizado com seis repetições para cada tratamento. A existência de diferenças significativas entre os tratamentos foi testada via Análise de Variância (ANOVA), seguido de teste de comparação de médias de Tukey em caso de positivo, ao nível de $1 \%$ de significância. A análise de regressão foi realizada utilizando o software Excel ${ }^{\circledR}$.

A preservação dos isolados foi feita em água destilada estéril (FIGUEIREDO, 1967). Utilizando frascos de vidro de $10 \mathrm{~mL}$ preenchidos com água ultrapurificada, seguido de autoclavagem a $120{ }^{\circ} \mathrm{C}$ por $30 \mathrm{~min}$. A transfeência dos discos de micélio das colônias de isolados para os frascos foi realizada em câmara de fluxo laminar, com o auxílio de um bisturi. Os frascos foram lacrados, identificados e depositados na Coleção de Fungos e Oomicetos Florestais da Embrapa Florestas.

\section{RESULTADOS E DISCUSSÃO}

\section{Isolados obtidos}

A partir do material com sintomas de antracnose (Figura 1) submetidos ao isolamento direto e indireto, foram obtidos 15 isolados de Colletotrichum spp. e nove Isolados de Fusarium spp.. Além destes, também foram encontrados isolados dos gêneros Phomopsis, Chaetomium, Xylaria, Cladosporium, Alternaria e Pestalotiopsis. Outros isolados não puderam ser identificados por não apresentarem estruturas reprodutivas.

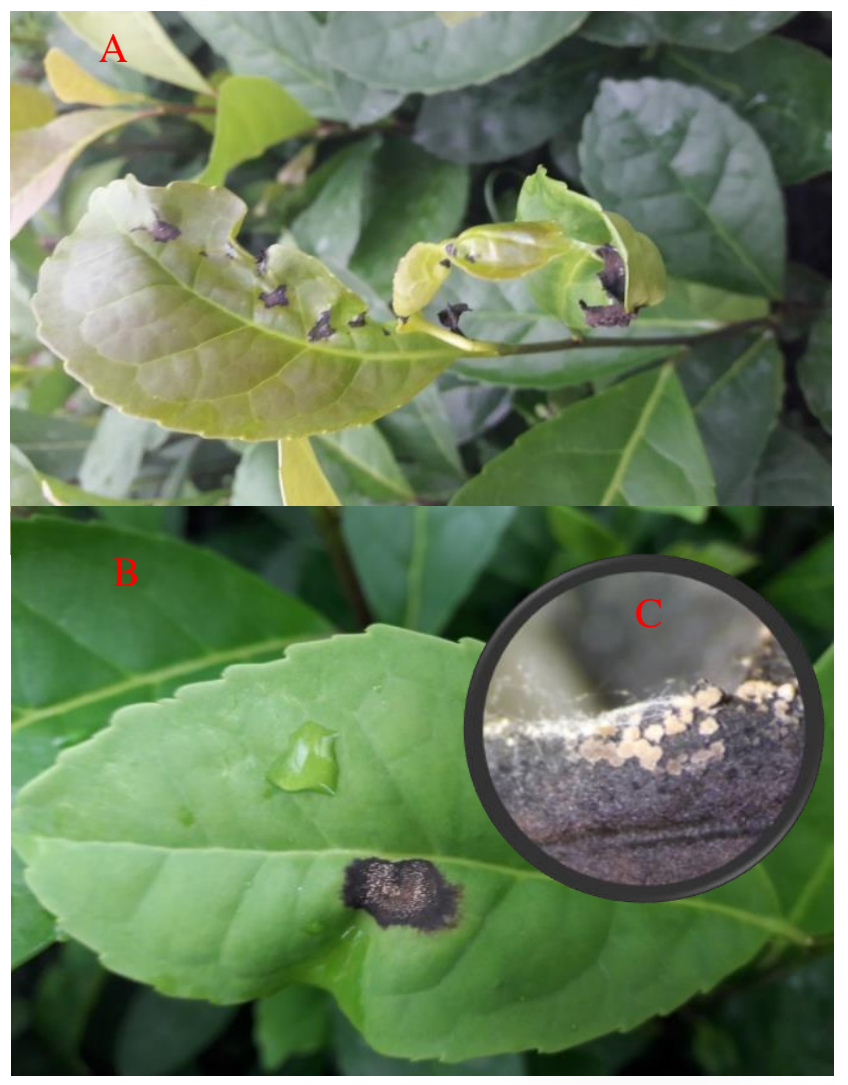

Figura 1. Sintomas típicos de antracnose em mudas de erva-mate. A deformação de folhas jovens; B lesão com esporulação do fungo; $C$ detalhe de acérvulos e massa de esporos ao microscópio estereoscópico.

\section{Características culturais e morfologia dos conídios}

Houve variação para as características cor, aspecto, altura e densidade das colônias (Figura 2, Tabela 2). Para coloração, quatro isolados apresentaram cor salmão, três com coloração laranja e dois isolados com coloração creme. Algumas colônias apresentaram mudança de coloração após avaliação, como ocorreu com o isolado CM-b1 que mudou de coloração salmão para cinzaescuro, e para o isolado de GUA-1 que passou da cor creme paralaranja-claro. Desse modo pode-se verificar a presença de dois ou três morfotipos, o que indicaria mais de uma espécie de Colletotrichum. Para altura da 
colônia, todos os isolados apresentaram colônias baixas, com exceção dos isolados CM-b2 e UV-1 cujo crescimento ocorreu rente à superfície do meio de cultura, com pouco micélio aéreo. Aparentemente, não houve relação entre essas características e o local de origem.

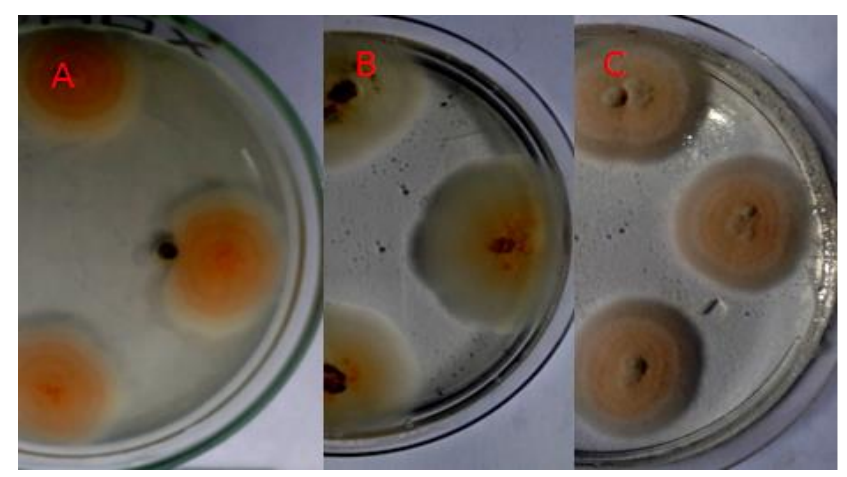

Figura 2. Tipos de colônias de Colletotrichum spp. quanto à coloração, altura e densidade. - A Laranja/baixo/denso; B - Creme/rente/denso; C - Salmão/baixo/denso.

Tabela 2. Características culturais e morfologia dos conídios de nove isolados de Colletotrichum spp. isolados de plantas de erva-mate provenientes de quatro diferentes regiões do Paraná.

\begin{tabular}{|c|c|c|c|}
\hline Isolado & Coloração & $\begin{array}{c}\text { Altura de } \\
\text { crescimento e } \\
\text { densidade }\end{array}$ & $\begin{array}{c}\text { Conídio } \\
\text { (forma } \\
\text { frequente) }\end{array}$ \\
\hline CM-a1 & Laranja & Rente, intermediário & Cilíndrico \\
\hline CM-a2 & Salmão & Baixo, denso & Cilíndrico \\
\hline CM-a3 & Laranja & Baixo, denso & Cilíndrico \\
\hline CM-b1 & Salmão & Baixo, intermediário & Cilíndrico \\
\hline CM-b2* & Creme & Rente, intermediário & Cilíndrico \\
\hline UV-1* & Laranja & Rente, intermediário & Cilíndrico \\
\hline UV-2 & Salmão & Baixo, denso & Cilíndrico \\
\hline GUA-1* & Creme & Rente, denso & Ovoide \\
\hline COL-1* & Salmão & Baixo, denso & Fusiforme \\
\hline
\end{tabular}

CM - Cruz Machado, UV - União da Vitória, GUA - Guarapuava, COL - Colombo. *Isolados utilizados no ensaio de crescimento.

Quanto aos esporos, estes se mostraram diversificados em forma e tamanho, sendo o tipo cilíndrico o mais encontrado neste estudo, podendo isolado apresentar mais de um tipo de conídio (Figura 3). Fungos do complexo Colletotrichum gloeosporioides (Penz.) Penz. \& Sacc. apresentam conídios mais cilíndricos, enquanto no complexo $C$. acutatum os conídios são de formato fusiforme (SUTTON, 1992). Desse modo, tal como houve indicação de mais de uma espécie pela presença de mais de um morfotipo, os dois tipos de conídios verificados, indicam que os isolados pertencem aos diferentes complexos de Colletotrichum.

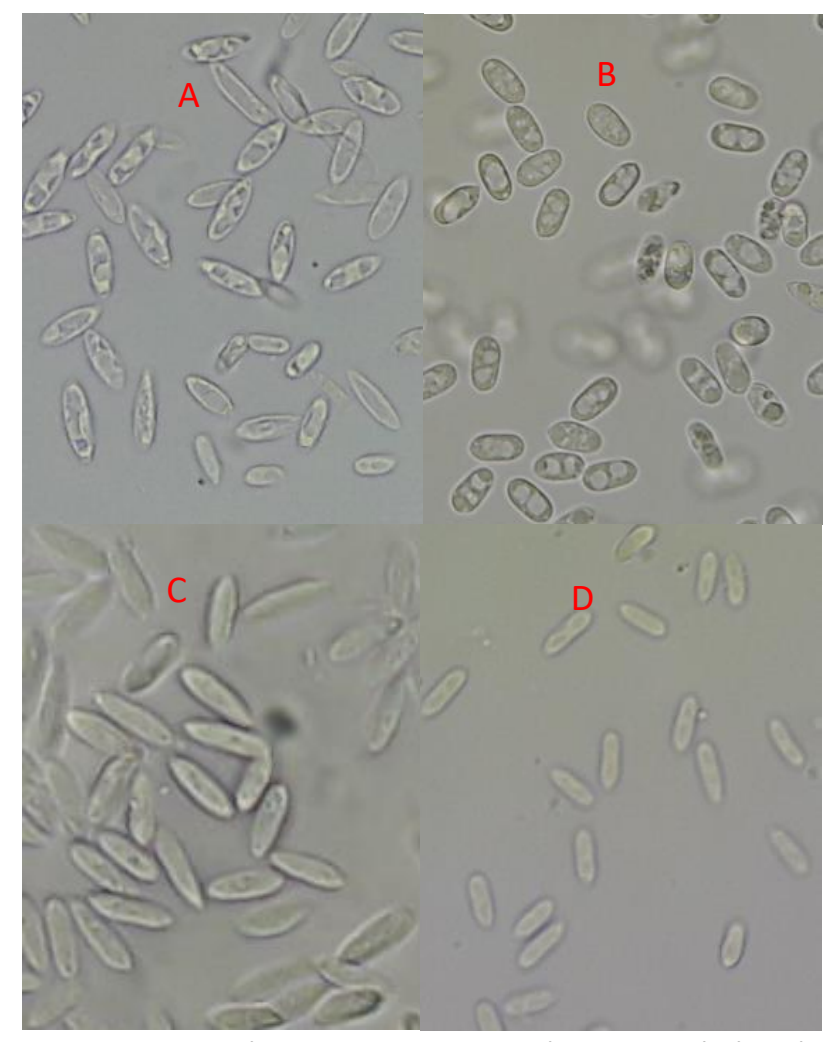

Figura 3. Tipos de esporos encontrados nos isolados de Colletotrichum spp.: A - Cilíndrico; B - Cilíndrico com ápice pontiagudo; C - Ovoide e D Fusiforme.

Almeida (2015), trabalhando com isolados de Colletotrichum spp. obtidos de plantas de Annona spp., notou que todos os isolados do complexo $C$. acutatum apresentaram coloração salmão, com conídios cilíndricos, retos e fusiformes ocorrendo nesse grupo; no complexo $C$. boninense, dois isolados apresentaram coloração marrom escuro e um isolado coloração cinzaclaro, com conídios cilíndricos e clavados; no complexo $C$. gloesporioides foi observada uma grande variação quanto a coloração (marrom-claro, cinza-escuro, cinzaclaro, salmão, branco). Silva et al. (2018) trabalharam com isolados de Colletotrichum spp. obtidos de plantas de Capsicum chinense Jacq. (pimenta-de-cheiro), a maior parte dos isolados $(87,5 \%)$ apresentaram coloração de colônia cinza (cinza cinza-claro e cinza-escuro) e os demais, coloração branca.

Os tipos de conídios encontrados foram retos, oblongos e com ápices arredondados. Hayer (2010) 
dividiu as colônias de Colletotrichum spp. coletados de Hevea brasiliensis (seringueira) em dois grupos de coloração; o primeiro grupo abrangeu a maioria dos isolados, com coloração das colônias de laranja-cinza a laranja; o segundo grupo apresentou coloração cinzaclaro. Nesses estudos, o uso de caracteres morfológicos (tamanho e formato de conídios e apressórios) e culturais (coloração, taxa de crescimento micelial e topografia das colônias) não permitiu a identificação ao nível de espécie, embora muitas dessas características se ajustem às descritas na literatura para as respectivas espécies.

\section{Ensaios de temperatura}

A temperatura de incubação que resultou no maior crescimento micelial para todos os isolados foi $24{ }^{\circ} \mathrm{C}$ (Tabela 2, Figura 4). Comparando o crescimento dos diferentes isolados em cada temperatura, houve diferença significativa para crescimento micelial nas temperaturas de 16,20 e $32{ }^{\circ} \mathrm{C}$. Para as temperaturas mais baixas, o isolado de Guarapuava (GUA-1) apresentou o maior crescimento, enquanto o isolado UV1 foi o com menor crescimento. Para a temperatura mais elevada $\left(32^{\circ} \mathrm{C}\right)$, o isolado $\mathrm{CM}$-b2 apresentou crescimento significativamente maior que os demais. $\mathrm{O}$ isolado GUA-1 não apresentou crescimento na temperatura de $32{ }^{\circ} \mathrm{C}$.

Tabela 3. Crescimento micelial de quatro isolados de Colletotrichum após cinco dias de incubação sob cinco temperaturas e fotoperíodo de 12 horas, em meio BDA.

\begin{tabular}{cccccc}
\hline \multirow{2}{*}{ Isolado } & \multicolumn{5}{c}{ Temperatura $\left({ }^{\circ} \mathbf{C}\right)$} \\
\cline { 2 - 6 } & $\mathbf{1 6}$ & $\mathbf{2 0}$ & $\mathbf{2 4}$ & $\mathbf{2 8}$ & $\mathbf{3 2}$ \\
\hline UV-1 & $11,60 \mathrm{Dc}$ & $17,50 \mathrm{Cc}$ & $25,42 \mathrm{Aa}$ & $21,01 \mathrm{Ba}$ & $1,43 \mathrm{Ec}$ \\
COL-1 & $14,19 \mathrm{Cb}$ & $21,00 \mathrm{Bb}$ & $26,89 \mathrm{Aa}$ & $22,27 \mathrm{Ba}$ & $2,57 \mathrm{Db}$ \\
GUA-1 & $16,52 \mathrm{Ca}$ & $24,66 \mathrm{Ba}$ & $27,74 \mathrm{Aa}$ & $23,13 \mathrm{Ba}$ & $0,00 \mathrm{Dd}$ \\
CM-b2 & $13,86 \mathrm{Cb}$ & $22,25 \mathrm{Bb}$ & $26,09 \mathrm{Aa}$ & $21,72 \mathrm{Ba}$ & $6,60 \mathrm{Da}$ \\
\hline
\end{tabular}

Médias seguidas da mesma letra, Maiúsculas nas linhas e minúsculas nas colunas, não diferem entre si pelo teste de Tukey a $1 \%$ de probabilidade. Isolado: UV - União da Vitória, COL - Colombo, GUA - Guarapuava e CM - Cruz Machado. CV: $7,57 \%$.

Através da análise de regressão, encontrou-se o ponto de crescimento máximo das culturas em temperaturas em torno de $23{ }^{\circ} \mathrm{C}$ para os isolados de UV1 , COL-1 e CM-b2 e de $22,6{ }^{\circ} \mathrm{C}$ para o isolado de Guarapuava (GUA-1) (Figura 5).

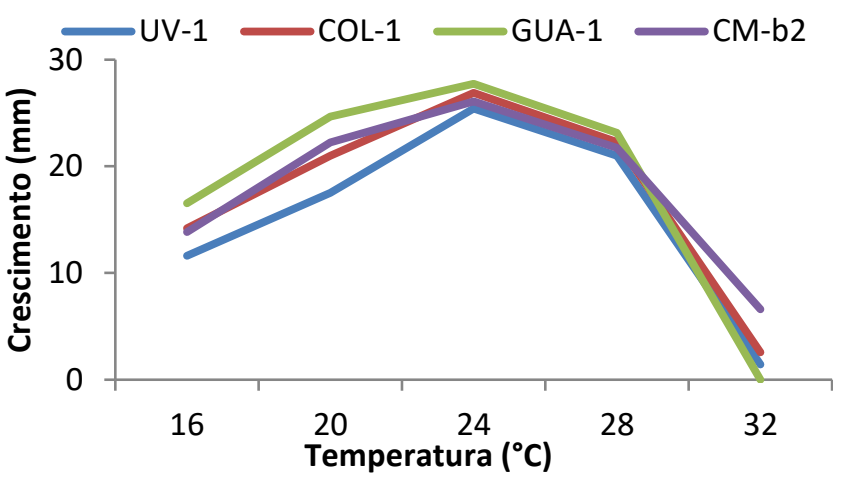

Figura 4: Crescimento micelial de isolados de Colletotrichum spp. após quatro dias de cultivo em cinco temperaturas, sob fotoperíodo de 12 horas, em meio BDA. UV = União da Vitória $\mathrm{COL}=$ Colombo, GUA = Guarapuava e CM = Cruz Machado.

O crescimento de fungos filamentosos é complexo, e pode ser definido como um incremento ordenado de componentes celulares, com consequente aumento de biomassa (PROSSER, 1995). Os fungos filamentosos podem ser cultivados em meios líquidos ou sólidos sintéticos em laboratório (WALKER et al., 2017). Esse crescimento pode ser medido por métodos diretos (diâmetro de colônia crescimento em extensão da hifa e medida da biomassa) e métodos indiretos (ergosterol, adenosina trifosfato, pectina esterase, entre outros) (MARTÍ, 2006).

Muitos fatores de ordem ambiental, biológica, física e química podem afetar o desenvolvimento micelial dos fungos (WALKER et al., 2017) e dessa forma estes têm se diversificado ao longo da evolução a fim de explorar diferentes habitats (MARTí, 2006). A umidade tem papel crucial, pois afeta a sobrevivência do inóculo, a disseminação e o processo infeccioso do patógeno, tendo portanto uma mais marcante que a temperatura, visto que a maioria dos patógenos é capaz de crescer em uma ampla faixa de temperaturas (AMORIM et al., 2018). Há poucos estudos reeferentes a influência do $\mathrm{pH}$ sobre o crescimento de Colletotrichum, de acordo com Duarte et al. (1982), para C. corchorum a faixa de pH entre 5,5 e 6,5 foi a que mais favoreceu o crescimento do fungo.

De acordo com Vinnere (2004), a temperatura ótima para crescimento de $C$. acutatum está entre 25 e $25,4{ }^{\circ} \mathrm{C}$, com temperatura máxima de $33{ }^{\circ} \mathrm{C}$. Para $\mathrm{C}$. gloesporioides a temperatura ótima estaria entre 26 e $28,5^{\circ} \mathrm{C}$, com temperatura máxima de $35,5^{\circ} \mathrm{C}$. Ainda de acordo com esse autor, geralmente $C$. acutatum apresenta um crescimento mais lento que $C$. gloesporioides, sendo essa a única característica que 
parece ser realmente estável e confiável na separação das espécies. Resultados concordantes com essa característica foram relatados por Sussel (2005).
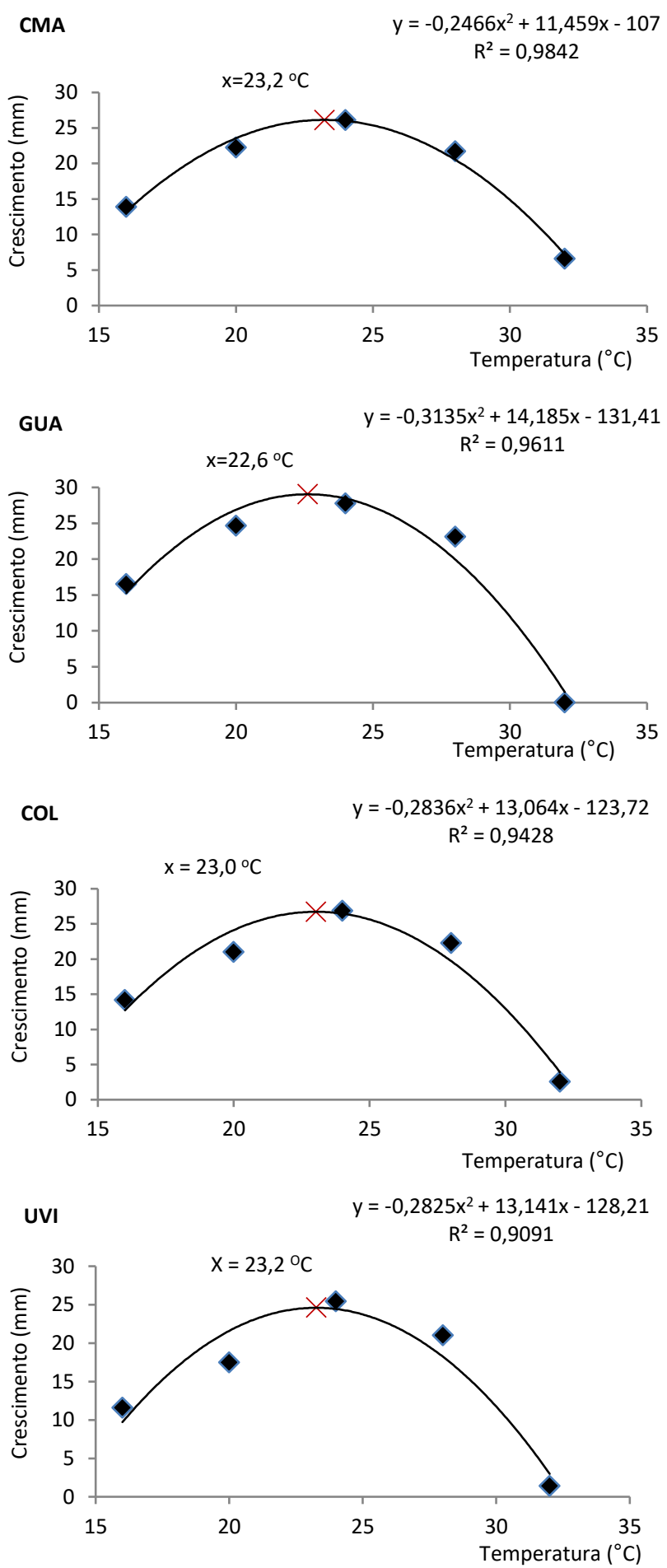

Figura 5. Análise de regressão dos dados de crescimento micelial de quatro isolados de Colletotrichum após quatro dias de cultivo em cinco temperaturas, em meio BDA. UVI = União da Vitória, $\mathrm{COL}=$ Colombo, GUA = Guarapuava e $\mathrm{CMA}=$ Cruz Machado. $\mathrm{x}=$ Ponto de crescimento máximo do fungo.

No entanto, Hayer (2010) observou resultado inverso ao estudar o crescimento micelial de seis isolados de Colletotrichum pertencentes às espécies $C$. acutatum e $C$. gloesporioides, coletados de diferentes partes da seringueira, com crescimento menor de $C$. gloesporioides. Ainda de acordo com esse autor, para as seis diferentes temperaturas testadas $(10,15,20,25,30$ e $35{ }^{\circ} \mathrm{C}$ ), o maior crescimento foi observado a $25{ }^{\circ} \mathrm{C}$, assim como um dos isolados de $C$. gloeosporioides se desenvolveu bem também à temperatura de $30^{\circ} \mathrm{C}$.

Poltronieri et al. (2013) estudou a influência da temperatura no crescimento de quatro isolados de $C$. gloeosporioides coletados de frutos doentes da palmeira juçara (Euterpe edulis Mart). A temperatura ótima para todos os isolados foi de $28{ }^{\circ} \mathrm{C}$ (dados brutos) e de $24,6{ }^{\circ} \mathrm{C}$ (análise de regressão), com o crescimento dos isolados totalmente inibido na temperatura de $35^{\circ} \mathrm{C}$.

Rêgo et al. (2015) avaliou a influência da temperatura no crescimento micelial de $C$. gloeosporioides f. SP. Cepae obtido a partir de plantas de cebola (Allium cepa L.). $\mathrm{O}$ isolado apresentou crescimento na faixa de 15 a 40 ${ }^{\circ} \mathrm{C}$, com temperatura ótima de $28,39^{\circ} \mathrm{C}$.

Maia et al. (2010) estudou o efeito da temperatura no crescimento micelial de Colletotrichum spp. Isolados a partir da mangueira (Mangifera indica L.) e todos os isolados testados apresentaram melhor crescimento em temperaturas entre 20 e $25^{\circ} \mathrm{C}$.

De acordo com o atlas climático do Estado do Paraná elaborado por Nitsche et al. (2019), as regiões onde foram coletados os isolados apresentam temperaturas muito semelhantes, não diferindo mais que $1{ }^{\circ} \mathrm{C}$ entre si. As características climáticas particulares de cada local podem estar relacionadas com a fisiologia dos isolados e explicar a variação no crescimento nas temperaturas testadas. De acordo com Sutherst et al. (1996), os patógenos de plantas respondem rapidamente às mudanças do ambiente, devido às numerosas populações existentes e o curto intervalo entre gerações.

Este estudo foi o primeiro passo para avaliar os isolados de Colletotrichum spp. em erva-mate. Estudos de caracterização morfológica de estruturas reprodutivas e moleculares e de fatores relacionados com a epidemiologia da doença também precisam ser realizados.

\section{CONCLUSÃO}

Os isolados de Colletotrichum apresentam variação na coloração das colônias, com predomínio de colônias de coloração salmão e pouco cotonosas. A forma dos conídios varia entre cilíndrico (mais comum), fusiforme, ovoide e cilíndrico com ápice arredondado, típicos de 
espécies de Colletotrichum. A temperatura de máximo crescimento micelial dos isolados está em torno de $23^{\circ} \mathrm{C}$.

\section{AGRADECIMENTOS}

À Uniguaçu e Embrapa Florestas, pela cessão dos laboratórios e apoios para realizar o estudo. Ao CNPq, pela bolsa de produtividade do segundo autor.

\section{REFERÊNCIAS}

ALMEIDA, C.A. Diversidade e caracterização de espécies de Colletotrichum associadas a Annona spp. 2015. 75p. (Dissertação de Mestrado).

AMORIM, L. et al. Manual de fitopatologia: princípios e conceitos. 5. ed. Ouro Fino: Ceres, 2018.

AUER, C. G.; SANTOS, A.F. Doenças da erva-mate. Manual de fitopatologia: doenças das plantas cultivadas. 5. ed. Ouro Fino: Agronômica Ceres, 2016.

CANNON, P.F. et al. Colletotrichum - current status and future directions. Studies in Mycology, v.73, p.181-213, 2012.

COLPO, A.Z.C. Perfil fitoquímico e capacidade antioxidante de extratos de erva-mate (Ilex paraguariensis A. St. Hill.). 2012. 86p. (Dissertação de Mestrado).

DUARTE, M.L.R et al. Influência de meios de cultura, pH e do regime luminoso no crescimento e esporulação de Colletotrichum corchorum lkata \& Tana. Embrapa Amazônia Oriental: publicações, 1982. Disponível em: https://www.infoteca.cnptia.embrapa.br/bitstream/doc/38230 0/1/CPATUBP48.pdf.

FIGUEIREDO, M.B. Estudos sobre a aplicação do método de Castellani para conservação de fungos patógenos de plantas. $\mathbf{O}$ Biológico, v.33, p.9-13, 1967.

GOMES, N.S.B. et al. Patogenicidade de Colletotrichum acutatum em folhas destacadas de erva-mate. Boletim de Pesquisa Florestal, n.43, p.151-154, 2001.

HAYER, J.F.S. Caracterização e controle de Colletotrichum spp. em seringueira (Hevea brasiliensis). 2010. 68p. (Dissertação de Mestrado).

LUTOMSKI, P. et al. Health properties of Yerba Mate. Annals of Agricultural and Environmental Medicine, v.27, n.2, p.310-313, 2020.

MAIA, F.G.M. et al. Efeito da temperatura no crescimento micelial, produção e germinação de conídios de Colletotrichum spp. isolados de mangueira com sintomas de antracnose. Bioscience Journal, v.27, n.2, p.205-210, 2011.

MARTí, N.B. Ecophysiology of ochratoxigenic moulds. Ochratoxin $A$ and ochratoxigenic modulds in grapes, must and wine. ecophysiological studies. p.243-418. Lérida: TDX, 2006. Disponível em: https://www.tdx.cat/bitstream/handle/10803/ 8376/Tbmn13de18.pdf? sequence $=4$ \&isAllowed $=y$

NITSCHE, P.R. et al. Atlas climático do Estado do Paraná. Instituto Agronômico do Paraná, 2019. Disponível em:
http://www.iapar.br/arquivos/File/zip_pdf/AtlasClimaticoPR.pd f.

POLTRONIERI, T.P.S. Efeito da temperatura no crescimento micelial, produção e germinação de conídios de Colletotrichum gloeosporioides, isolados de frutos de palmeira juçara (Euterpe edulis Mart). Summa Phytopathologica, v.39, n.4, p.281-285, 2013.

PROSSER, J.I. Kinetics of filamentous growth and branching. The growing fungus. Chapman and Hall: London, UK. 1994.

PENTEADO JUNIOR, J.F.; GOULART, I.C.G.R. Erva 20: sistema de produção para erva-mate. Brasília: Embrapa, 2019.

PORFÍRIO-DA-SILVA, V. et al. Seminário Erva-mate XXI: modernização no cultivo e diversificação do uso da erva-mate. Anais. Embrapa Florestas, 2016. Disponível em: https://www.infoteca.cnptia.embrapa.br/infoteca/bitstream/d oc/1060432/1/Doc.298Seminarioervamate.pdf.

PUANGPRAPHANT, S. Anti-inflammatory and anti-colon cancer potential of yerba mate (Ilex paraguariensis St. Hilaire) bioactive constituents. 2011. 188p. (Tese de doutorado).

RÊGO, M.T.C. et al. Crescimento e esporulação de Colletotrichum gloeosporioides f.sp. cepae sob diferentes temperaturas. Embrapa Semiárido: publicações, 2015. Disponível em: https://www.embrapa.br/busca-depublicacoes/-/publicacao/1019203/crescimento-e-esporulacaode-colletotrichum-gloeosporioides-fsp-cepae-sob-diferentestemperaturas.

SILVA, A.M. et al. Caracterização cultural, morfológica, molecular e patogênica de isolados de Colletotrichum spp. associados à antracnose da pimenta-de-cheiro (Capsicum chinense Jacq.) no estado do amazonas. Revista Agrária Acadêmica, v.1, n.4, p.39-51, 2018.

SUTHERST, R.W. et al. A generic approach to defining impacts of climate change on pests, weeds and diseases in Australasia. In: BOUMA, W.J. et al. (Eds.), Greenhouse: Coping with Climate Change. Melbourne Victoria, Austrália: CSIRO, p.281-307, 1996.

SUSSEL, A.A.B. Caracterização de isolados de Colletotrichum lagenarium, agente causal da antracnose das curcubitáceas. 2005. 68 p. (Dissertação de Mestrado).

SUTTON, B.C. The genus Glomerella and its anamorph Colletotrichum. Colletotrichum: biology, pathology and control. Wallingford: Redwood, 1992.

VINNERE, O. Approaches to species delineation in anamorphic (mitosporic) fungi: a study on two extreme cases. Uppsala: Department of evolutionary biology Faculty of Science and Technology, 2004.

WALKER, G.M.; WHITE, N.A. Introduction to fungal physiology. Fungi: biology and applications. 3.ed. West Sussex: Wiley, 2017.

WENDLING, I. et al. Manual de produção de mudas clonais de erva-mate. Colombo: Embrapa Florestas, 2020. (Embrapa Florestas. Documentos, 336).

Recebido em 12-01-2021 Aceito em 26-04-2021 